\title{
Large planar dielectric elastomer actuators for fish-like propulsion of an airship
}

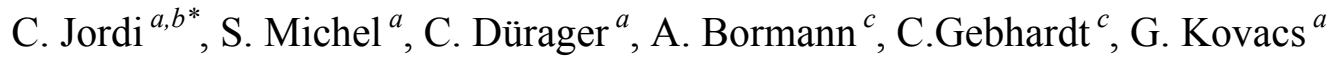 \\ ${ }^{a}$ Empa, Swiss Federal Laboratories for Materials Testing and Research, Laboratory for Mechanical \\ Systems Engineering, Uberlandstr. 129, 8600 Dubendorf, Switzerland \\ ${ }^{b}$ ETH, Swiss Federal Institute of Technology Zurich, Centre of Structure Technologies, Switzerland \\ ${ }^{c}$ Aeroix GmbH, Berlin, Germany
}

\begin{abstract}
One of the great advantages of dielectric elastomers (DE) is their scalability. Large planar DE are quite unique in the world of actuators. An interesting application of such actuators is the activation of inflatable structures. As research platform a model airship of $8 \mathrm{~m}$ in length was constructed that can move its body and tail fin in a fish-like manner. Unlike the propulsion with propellers, the fish-like movement is silent and the airflow around the airship is not disturbed. The bending actuation of the helium-filled hull is realized with planar two-layered DE of $1.6 \mathrm{~m}^{2}$ on either side. The tail fin is moved by four-layer planar DE of $0.3 \mathrm{~m}^{2}$ on either side. A design for actuators of such dimensions was developed and the actuators were characterized in terms of their performance.
\end{abstract}

Keywords: Dielectric elastomers (DE), Electro-active polymers (EAP), Airship, Fish-like propulsion, Biomimetics

\section{INTRODUCTION}

Dielectric elastomer actuators consist of a dielectric membrane coated on both sides with a compliant electrode. This simple set-up leads to a number of advantages, among which scalability has often been mentioned ${ }^{1-3}$. Large planar membrane dielectric elastomer actuators are needed for applications that require large displacements or large force. An interesting application of such actuators is e.g. the activation of inflatable structures. Their light-weight, soft and flexible structure can easily be integrated or applied onto the inflated membrane. The context of the present investigation is an airship that can move its body and tail fin in a fish-like manner based on planar DE actuators. The size of the actuators is determined by the size and movement (vortices, thrust) of the airship ${ }^{4}$. The fish-like movement is potentially very efficient over a large range of parameters and it is completely silent, whereas propellers are noisy and efficient only within a narrow parameter range (e.g. a certain rotary speed) ${ }^{5,6}$.

*christa.jordi@empa.ch; phone +41-44-823 4772; fax +41 44823 4011; www.empa.ch/airship

Electroactive Polymer Actuators and Devices (EAPAD) 2010, edited by Yoseph Bar-Cohen, Proc. of SPIE Vol. 7642, 764223 - (c) 2010 SPIE · CCC code: 0277-786X/10/\$18 - doi: 10.1117/12.847854

Proc. of SPIE Vol. 7642 764223-1 
In a first part, the airship, its passive components and its configuration in general is described. The main part of this work then concentrates on the up-scaling of DE actuators. It considers the effect of size on manufacturing and performance and points out the limitations. In the last part, the control unit is described as it is a novel combination of ultra-lightweight high voltage components.

\section{FISH-LIKE AIRSHIP CONFIGURATION}

The model airship has a total length of $8 \mathrm{~m}$, it is up to $2 \mathrm{~m}$ high and $1.5 \mathrm{~m}$ wide. It consists of a rigid inner structure, a helium-inflated hull, a tail fin, six actuators and the gondola with the electronics (Fig.1). The inner structure in the center is made of carbon fibre reinforced plastic (CFRP). This "backbone" maintains the fish-like shape by creating a lensshaped cross-section. It creates a defined bending-point of the body and absorbs some of the forces from the actuators and the gondola. The hull consists of Heptax (by Aeroix), which is a helium-tight material that is weldable and weighs only $25 \mathrm{~g} / \mathrm{m}^{2}$. Where the actuators are attached the hull is constricted to eliminate direct contact between the hull material and the DE actuators (Fig.2). Moving the actuators against the hull membrane has led to friction, constraining the free displacement, and abrasion of the actuators. There are three parts of the gondola which are all attached to the bottom side of the airship. Through their positioning along the length of the airship, the pitching moment can be controlled.

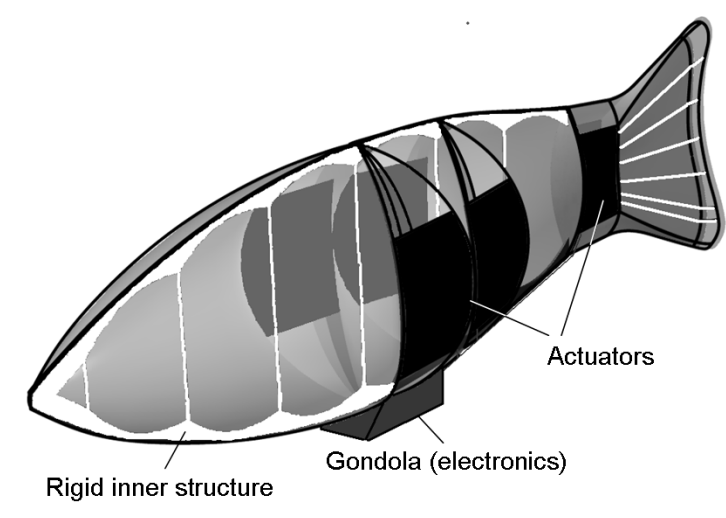

Fig. 1: Configuration of the model airship.

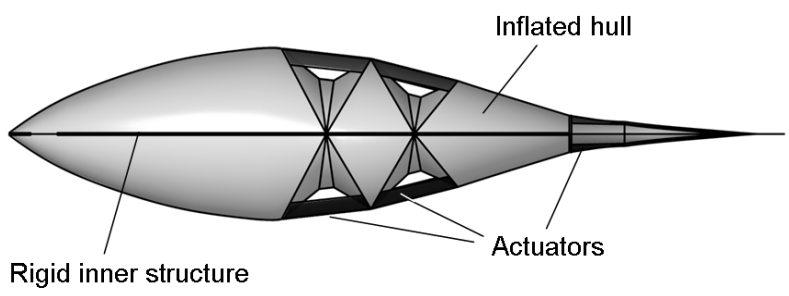

Fig. 2: Configuration of the model airship - top view.

There are two hinges within the body of the "fish", and two actuators on each side. The actuators are connected though and act as one unit on each side. The active length is given by the displacement that is needed at that point. The reason it is not realized with one single very long actuator is among others the manufacturing equipment, which limits the membrane size that we can pre-stretch. Also, the volume loss would have been too big with only one large constriction and the lift might therefore not have been sufficient.

The airship is filled with $11 \mathrm{~m}^{3}$ Helium and can lift approximately $8.9 \mathrm{~kg}$. The actuators, including fixations, weigh almost $1.7 \mathrm{~kg}$ and the electronics, power supply and control weigh another $3 \mathrm{~kg}$. Approximately $1 \mathrm{~kg}$ is trim weight or payload (Fig. 3). 


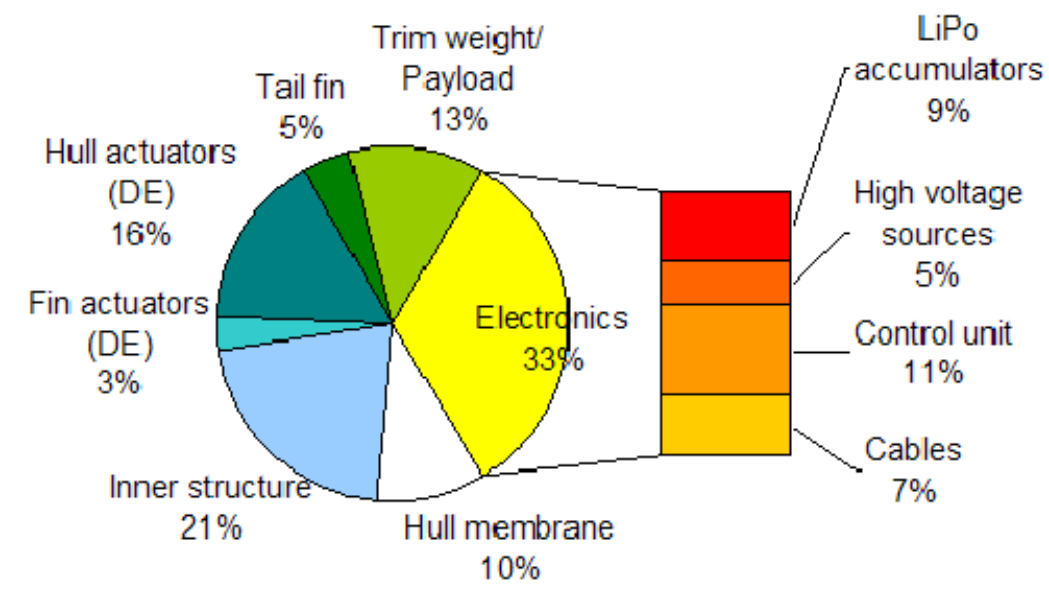

Fig. 3: Mass distribution of various components.

Fluid dynamical similarity calculations have been done for a $6 \mathrm{~m} \mathrm{model}^{4}$. Strouhal and Reynolds number are compared to those of a steady swimming rainbow trout (Assumptions: length $=0.3 \mathrm{~m}$, velocity $=1.2 \mathrm{~m} / \mathrm{s}$ at $4.5 \mathrm{~Hz})^{5}$. An activation frequency of $0.1 \mathrm{~Hz}$ can thus be calculated for the $8 \mathrm{~m}$ model airship (Eq. 1, 2). Desired angles for body and tail fin movement were determined. A velocity of up to $0.75 \mathrm{~m} / \mathrm{s}$ can be expected for the "air-fish" (Eq.3, 4).

$$
R e_{\text {trout }}=u \cdot l \cdot \rho / \mu=1.2 \mathrm{~m} / \mathrm{s} \cdot 0.3 \mathrm{~m} \cdot 1000 \mathrm{~kg} / \mathrm{m}^{3} / 1.002 \cdot 10^{-3} \mathrm{~kg} / \mathrm{ms}=0.36 \cdot 10^{6}=R e_{\text {airship }}
$$

$\mathrm{u}$ : swimming velocity, 1 : total length, $\rho$ : density of the fluid, $\mu$ : dynamic viscosity of the fluid

$$
\begin{aligned}
& u_{\text {airship }}=\operatorname{Re}_{\text {airship }} \cdot \mu /(l \cdot \rho)=0.36 \cdot 10^{6} \cdot 16.6 \cdot 10^{-6} \mathrm{~kg} / \mathrm{ms} /\left(8 \mathrm{~m} \cdot 1 \mathrm{~kg} / \mathrm{m}^{3}\right)=0.75 \mathrm{~m} / \mathbf{s} \\
& S t_{\text {trout }}=2 \cdot a \cdot f / u=0.12 \mathrm{~m} \cdot 4.5 \mathrm{~Hz} / 1.2 \mathrm{~m} / \mathrm{s}=0.45=S t_{\text {airship }}
\end{aligned}
$$

f: frequency, 2.a: Peak-to-peak amplitude [2]

$$
f_{\text {airship }}=S t_{\text {airship }} \cdot u /(2 \cdot a)=(0.45 \cdot 0.75 \mathrm{~m} / \mathrm{s}) / 3.2 \mathrm{~m}=\mathbf{0 . 1 1} \mathbf{H z}
$$

\section{LARGE-SCALE ACTUATORS}

\subsection{Experimental}

The large actuators are based on planar membrane actuators on a hinge that have been developed by Lochmatter ${ }^{7}$ (Fig.4). From these actuators the size of the actuators for the airship was calculated by assuming that the actuators scale according to theory (Chapter 3.2). The scaling effect was thoroughly investigated on actuators that are exactly five times larger in the planar dimensions and have three layers. 


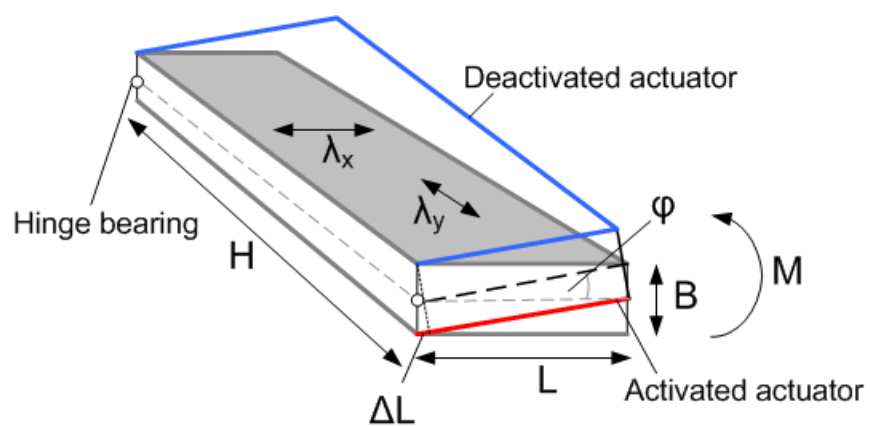

Fig. 4: Main dimensions of the active hinge with a deflection angel $\varphi$ and moment M. $\Delta \mathrm{L}$ is the difference in length between the active and passive actuator and $\lambda_{\mathrm{x}}$ and $\lambda_{\mathrm{y}}$ are the pre-stretch ratios in $\mathrm{x}$ and $\mathrm{y}$ direction.

Much attention must be paid to the detail when designing large actuators. Since the fabrication takes longer, it is more important to have a reasonable lifetime and not too much scrap during the manufacturing process. Local stress-peaks were a challenge when making the large-scale actuators. Therefore a new design was used, reinforcing the free end with a polyamide string or a rubber band between two layers (Fig. 5). All actuators are made of pre-stretched VHB 4910 (by 3M) with KetjenBlack600 (by Akzo Nobel) powder electrodes rubbed onto the dielectric. For the airship, the actuators were built with a higher pre-stretch in the direction perpendicular to the movement $\left(\lambda_{y}=6\right.$ instead of 5$)$ and they are reinforced with a polyamide string. The actuators for the hull are additionally reinforced with CFRP rods (Fig. 6). Their performance was tested only directly on the airship. The parameters of all actuators are listed in Table 1 .
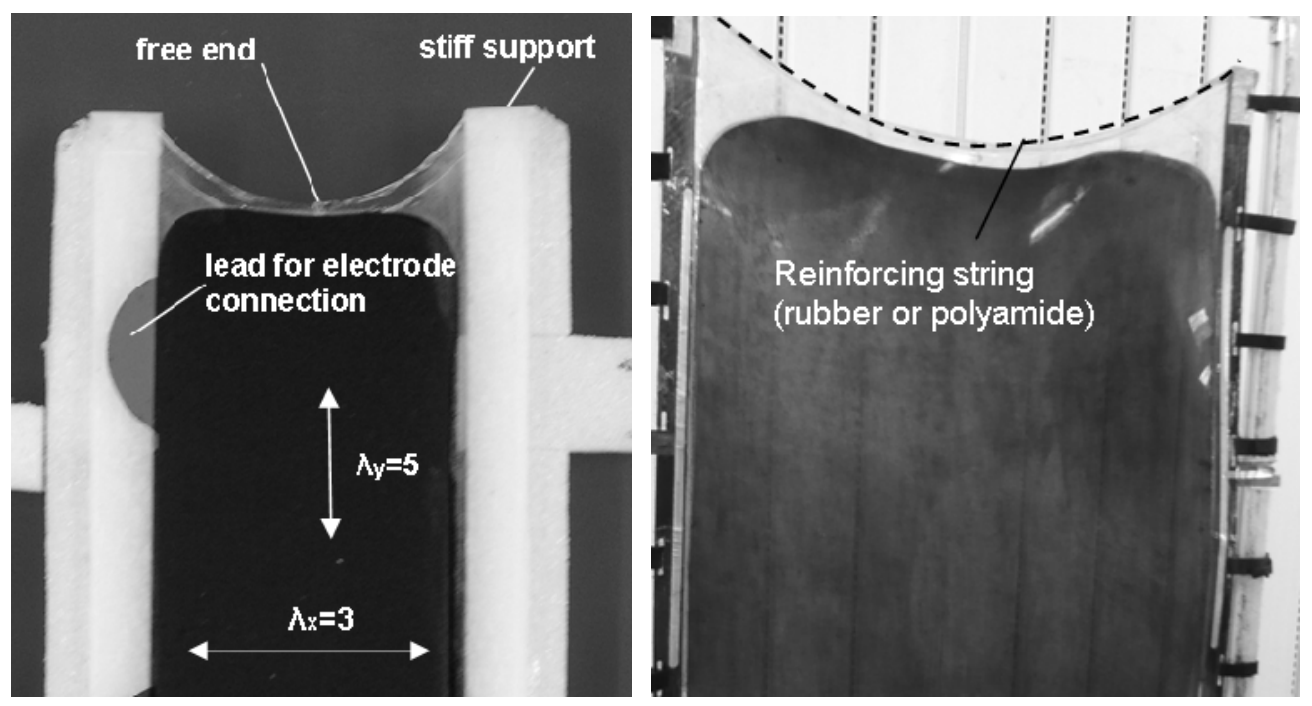

Fig. 5: A ,small“ actuator (left) and a five times larger actuator with internal string-reinforcement (right). 


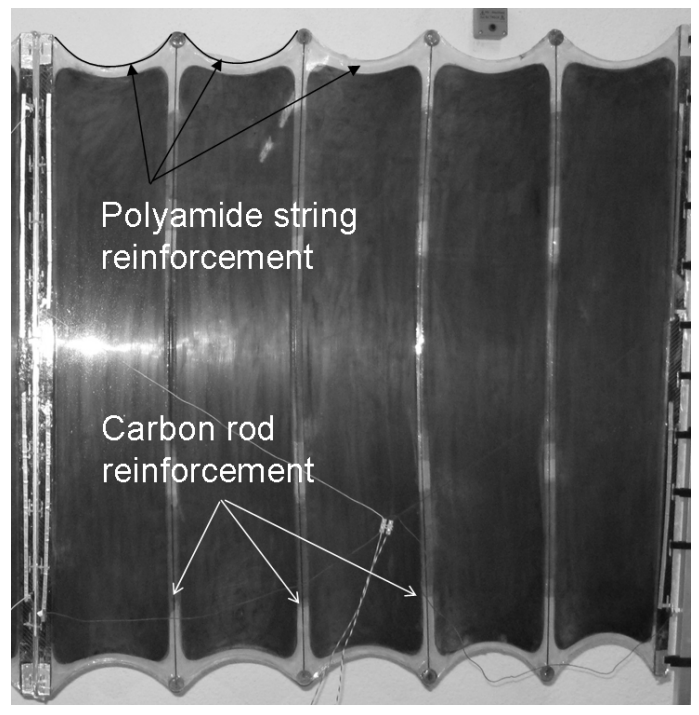

Fig. 6: Hull actuator.

Table 1: Design parameters for the "small" and "large" actuators and actuators on the airship.

\begin{tabular}{|c|c|c|c|c|}
\hline Design Parameters & Small actuator & Up-scaled actuator & Tail fin actuator & Hull actuator \\
\hline Dimensions Active (Height H, length L) & $0.19 \times 0.05 \mathrm{~m}$ & $0.95 \times 0.25 \mathrm{~m}$ & $0.95 \times 0.30 \mathrm{~m}$ & $5 \times 0.95 \times 0.13 \mathrm{~m}$ \\
\hline $\begin{array}{l}\text { Dimensions Total (H, L, including passive material } \\
\text { and stiff support at the ends) }\end{array}$ & $0.20 \times 0.055 \mathrm{~m}$ & $0.98 \times 0.32 \mathrm{~m}$ & $0.98 \times 0.35 \mathrm{~m}$ & $0.98 \times 0.84 \mathrm{~m}$ \\
\hline Width for calculating deflection angle/moment & $0.03 \mathrm{~m}$ & $0.15 \mathrm{~m}$ & (Triangular) & Approx. $1.5 \mathrm{~m}$ \\
\hline Pre-Stretch & $\lambda_{\mathrm{x}}=3, \lambda_{\mathrm{y}}=5$ & $\lambda_{\mathrm{x}}=3, \lambda_{\mathrm{y}}=5$ & $\lambda_{\mathrm{x}}=3, \lambda_{\mathrm{y}}=6$ & $\lambda_{\mathrm{x}}=3, \lambda_{\mathrm{y}}=6$ \\
\hline Number of dielectric layers & 1 and 3 & 3 & 3 & 2 \\
\hline Reinforcement & None & Elastic rubber band & Polyamide string & $\begin{array}{l}\text { Polyamide string and } \\
\text { carbon rods }\end{array}$ \\
\hline
\end{tabular}

For the characterization of the up-scaled actuators, a simplified planar agonist-antagonist test-stand was introduced instead of the hinge configuration (Fig.7). In this planar test rig two actuators are placed next to each other. They are attached to each other in a movable center-line, and fixed on both ends. While one actuator expands, the other contracts and the center-line will move to one side. The principle has been presented before ${ }^{1}$ as a double push-pull actuator. The force of the contracting actuator is similar as in the hinge configuration, without having additional friction and minimizing inertial forces. From the measured displacement of the center-line $(\Delta x)$, the angle that could be reached with the same actuators in a hinge configuration is determined by simple trigonometry (valid for small angles or small width/length ratios $\mathrm{B} / \mathrm{L}<<1$ ) (Eq.5). With Eq. 6 the blocking moment is calculated from the measured blocking force.

$$
\begin{aligned}
& \varphi=\arcsin (\Delta L / B)=\arcsin (2 \cdot \Delta x / B) \\
& M=\left(F_{b}-F_{a}\right) \cdot B / 2
\end{aligned}
$$



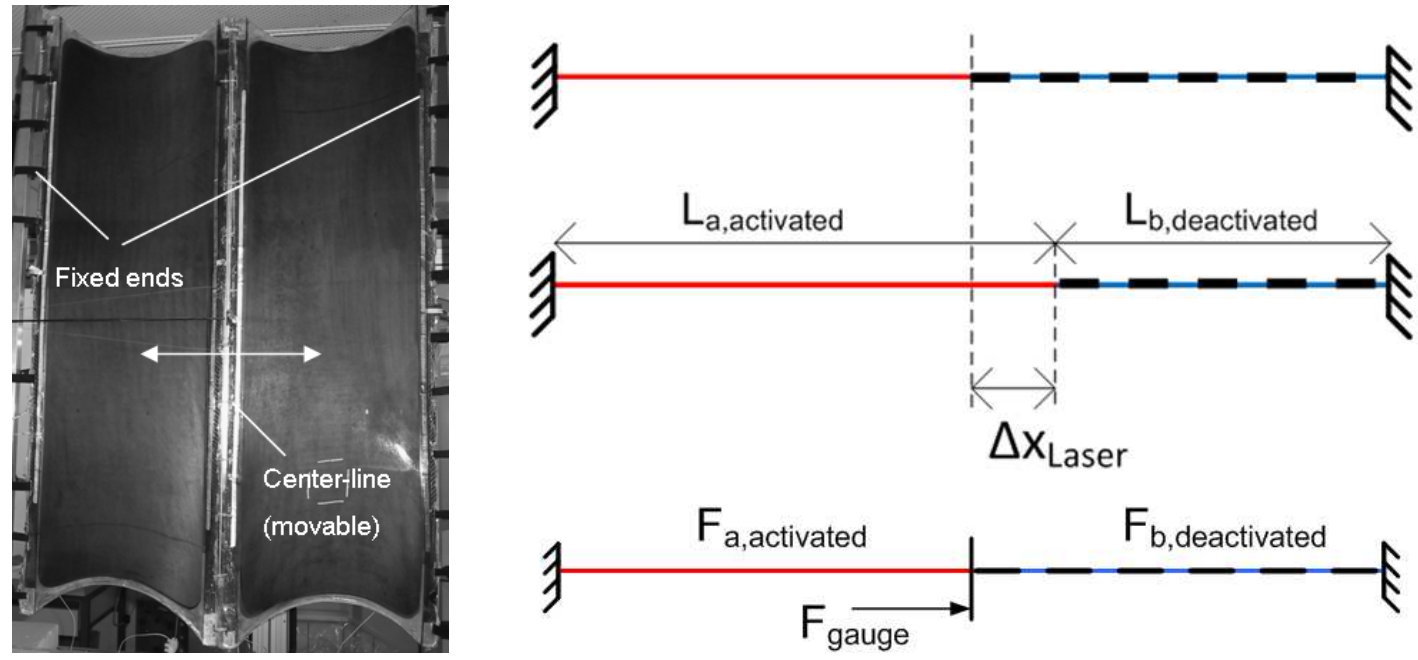

Fig. 7: Planar agonist-antagonist test-rig (left). Planar test rig, top view: Strain measurement with laser (top) and blocking force measurements with force gauge (bottom).

In the planar test-rig, the displacement of the center line $\left(\Delta \mathrm{x}_{\text {Laser }}\right)$ was measured with a laser sensor (Baumer electric OADM 2016460/S14F) and the blocking force $\left(\mathrm{F}_{\text {gauge }}\right)$ parallel to the actuators was measured with a force gauge (HBM type $\mathrm{S} 2,20 \mathrm{~N}=2 \mathrm{mV} / \mathrm{V}$ ). A high voltage amplifier (Trek Inc. model 5/80) was controlled with LabView and the voltage was switched to either actuator with a reed relay controlled by a frequency generator (HP 33120 A). All data was recorded with LabView. The input current and voltage were read directly from the voltage amplifier. The capacitance was estimated with different methods: The first method uses the relative permittivity of prestrained $\left(\lambda_{x}=3, \lambda_{y}=5\right) \mathrm{VHB} 4910$. Dielectric measurements were carried out with an Alpha Analyzer (Novocontrol) and Novocontrol HVB 1000 high-voltage test interface between $0.5 \mathrm{mHz}$ and $1 \mathrm{MHz}$. The dielectric membrane is held between two copper electrodes with a diameter of $25 \mathrm{~mm}$ and the relative permittivity is calculated from the capacitance. It was found to be approximately 3.1, which agrees well with previous results of other researchers ${ }^{8,9}$. For the actuator we can then determine the capacitance, using for area (A) and thickness (d) the final geometry after stretching (Eq.7).

$$
C=\varepsilon_{0} \cdot \varepsilon_{r} \cdot A / d
$$

A second method is calculating the charge and thus the capacitance (Eq.8).

$$
C=\int i(t) d t / U
$$

For the measurement on small actuators, a LCR meter (an instrument for measuring inductance, capacitance and resistance) (Agilent type $4263 \mathrm{~B}$ ) was used to measure the capacitance. It was not possible to measure the capacitance of large actuators directly; measuring with high frequencies $(100 \mathrm{~Hz}-1 \mathrm{kHz})$ the large actuators could not be fully charged in the available time. 
In the order of the methods described above we get for the small one-layered actuator: $4.6 \mathrm{nF}, 5.1 \mathrm{nF}, 5.4 \mathrm{nF}$. For the small three layered actuator: $13.7 \mathrm{nF}, 12.8 \mathrm{nF}, 11.8 \mathrm{nF}$ and for the large actuator: $350.7 \mathrm{nF}, 353.0 \mathrm{nF}$. The results of all three methods agreed well (differences of less than $10 \%$ ).

The resistance of the electrodes was calculated from current and voltage measurement $\mathrm{R}=\mathrm{U} / \mathrm{I}$. The measurements resulted in very inconsistent values for the large areas, varying over temperature, time, with activation voltage, mechanical strain or charging history. The measurements were therefore performed on small H-shaped samples of Ketjenblack600 coated on pre-stretched VHB $\left(\lambda_{x}=3, \lambda_{y}=5\right)$. Two copper blocks were placed on either side of the center line and the current between them was measured (Fig.8). The measured area is $10 \times 25 \mathrm{~mm}$ (w.b). At least five samples were made per test and six measurements per sample. The average specific sheet resistance is the resistivity ( $\rho$ ) divided by the layer thickness (d) and can be calculated with the area (w, b), voltage (U) and current (I): $R_{s}=\rho / d=U . w /(I . b)$. In order to determine the influence of the size on the sheet resistance, the measurement was scaled up by a factor of five and repeated.

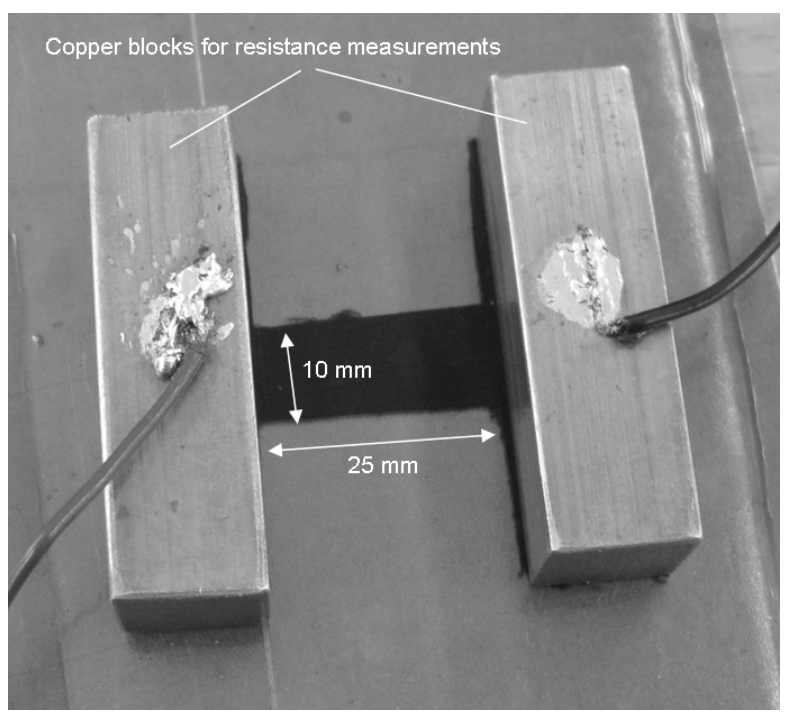

Fig. 8: Sheet resistance measurements with H-shaped samples.

\subsection{Scaling planar membrane DE}

Table 2 shows how various parameters depend on the actuator size. The scaling is expressed with a factor $\mathrm{S}$ for planar dimensions and $\mathrm{n}$ for the number of layers. For the large-scale actuators, $\mathrm{S}=5$ and $\mathrm{n}=3$ are used. The theoretical result is calculated from a small, one-layered actuator and compared to the large one at $3 \mathrm{kV}$ after $5 \mathrm{~s}$ activation. It can be seen that all deviations remain below $10 \%$ which proves that the actuators scale expectedly. 
Table 2: Scaling factors for various parameters and a comparison of the theoretical values, calculated from a small actuator and the measured values of a large actuator.

\begin{tabular}{|c|c|c|c|c|}
\hline \multirow{2}{*}{$\begin{array}{l}\text { Parameter } \\
\text { Displacement [m] }\end{array}$} & \multirow{2}{*}{$\begin{array}{l}\text { Scaling factor } \\
\mathrm{S}_{\text {large }} / \mathrm{s}_{\text {small }}=\mathrm{S}\end{array}$} & \multirow{2}{*}{$\begin{array}{l}\text { Estimation based on a small } \\
\text { 1-layered actuator } \\
4.0 .5=20 \mathrm{~mm}\end{array}$} & \multicolumn{2}{|c|}{$\begin{array}{l}\text { Results of the measurements } \\
\text { on large 3-layered actuator }\end{array}$} \\
\hline & & & $21 \mathrm{~mm}$ & $+5 \%$ \\
\hline Blocking Force $[\mathrm{N}]$ & $\mathrm{F}_{\text {large }} / \mathrm{F}_{\text {small }}=\mathrm{S} . \mathrm{n}$ & $0.7 .5 .3=10.5 \mathrm{~N}$ & $9.7 N$ & $-7.5 \%$ \\
\hline Capacitance $[\mathrm{F}]$ & $\mathrm{C}_{\text {large }} / \mathrm{C}_{\text {small }}=\mathrm{S}^{2} . \mathrm{n}$ & $5.1 .25 .3=382 n F$ & $350 n F$ & $-9 \%$ \\
\hline Sheet resistance $[\Omega / \mathrm{sq}]$ & $\mathrm{R}_{\mathrm{S} \_ \text {large }} / \mathrm{R}_{\mathrm{S}_{\_} \text {small }}=\mathrm{S}^{0}=1$ & $30.8 \Omega / s q$ & $27.9 \Omega / s q$ & $-9.4 \%$ \\
\hline Input Energy [J] & $\mathrm{W}_{\text {in_large }} / \mathrm{W}_{\text {in_small }}=\mathrm{S}^{2} . \mathrm{n}$ & $0.0456 .25 .3=3.42 \mathrm{~J}$ & $3.16 \mathrm{~J}$ & $-7.6 \%$ \\
\hline Output Energy [J] & $\mathrm{W}_{\text {out_large }} / \mathrm{W}_{\text {out_small }} \mathrm{S}^{2} . \mathrm{n}$ & $2.7 \mathrm{~mJ} .25 .3=0.20 \mathrm{~J}$ & $0.20 \mathrm{~J}$ & $0 \%$ \\
\hline Efficiency [-] & $\eta_{\text {large }} / \eta_{\text {small }}=S^{0}=1$ & $5.8 \%$ & $6.3 \%$ & $+8.6 \%$ \\
\hline
\end{tabular}

\subsection{Challenges and Limitations}

As mentioned in Chapter 3.1, much attention must be paid to constructive details. The increasing manufacturing time was for us an important reason to increase lifetime and diminish scrap during production. Local stress peaks where forces are introduced into the membrane have often lead to mechanical failure. Manufacturing tools must be designed to handle larger pieces and maintain the larger pre-stretching forces.

With increase in the area of the dielectric membrane, the number of defects (e.g. air bubbles) increases and with it the probability for electrical or mechanical failure. A testing series was made with 14 membranes of $0.8 \times 0.8 \mathrm{~m}$. Three different batches of VHB4910 were used and they were tested up to $63 \mathrm{~V} / \mu \mathrm{m}$ several times. From this measurement we get a probability of $14 \%$ that the membrane will fail and not be useful for our purpose. If we calculate the probability for failure of the small hinge actuators we get less than $0.5 \%$. For the large hull actuator on the other hand we get a probability of more than $30 \%$ that it will fail.

Safety is another issue varying with the actuators size. Discharging a capacitance of the size of our hull actuator through a human body may well be fatal.

\section{FLIGHT CONTROL}

The airship is controlled from a ground station unit. The signals are transmitted by a commercial Wireless-LAN module (WLAN) to the electronic steering device inside the gondola on the airship. For the ground station a commercially available laptop with LabView (by National Instruments) is used. All parameters that are needed for steering the airship, e.g. amplitude of the activation voltage, frequency and a phase shift between body and tail fin movement can be chosen on 
the ground station by the airship operator. The flight parameters can thus be changed online during the flight. Turns can be made by activating one side longer than the other.

The electronic steering device inside the gondola consists mainly of three parts:

- $\quad$ Lithium polymer accumulators (LiPo)

- Wireless steering unit

- High-voltage supply and switching unit

Due to their high energy density, two LiPo accumulators were used (each 2100mAh 4S1p 14.8V by Kokam) with a voltage of a total of $28 \mathrm{~V}$. The core part of the flight control unit is the wireless steering unit with an integrated microcontroller (ATMega2560 by AVR). It calculates the complex motion sequences depending on the parameters transmitted from the ground station. The microcontroller is connected directly to the high-voltage switching unit.

A relatively high current is needed for activating the large-scale actuators (high current peak at the beginning of the charging cycle). For this reason an electric switching unit was developed which enables us to switch part of the charge from one DE actuator to the actuator on the opposite side. With this loading technique it is possible to use smaller highvoltage supply units because the high current peak for loading the passive DE actuator is partly transferred from the active DE actuator. Figure 9 shows the equivalent circuit diagram of two DE actuators.

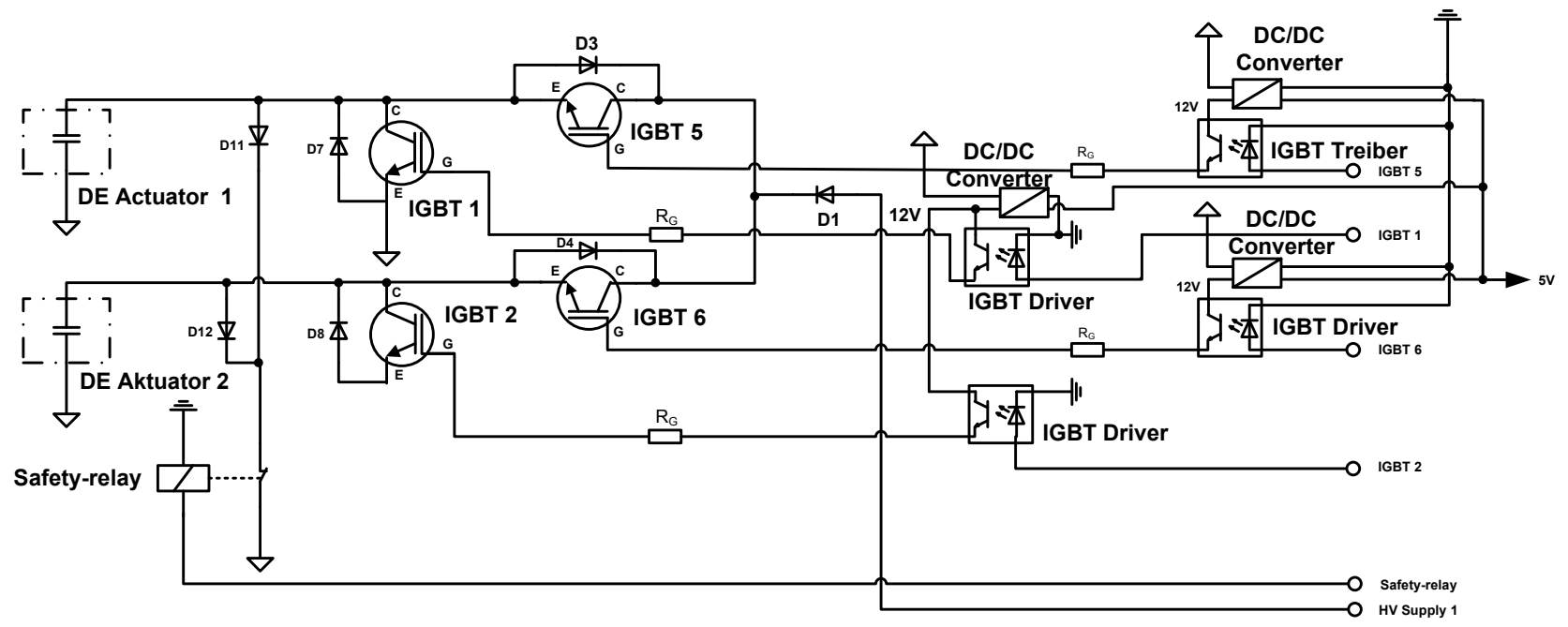

Fig. 9: Equivalent circuit diagram of the HV switching unit (for two DE actuators). IGBT 5 and 6 are for charging and IGBT 1 and 2 are for discharging the actuators.

For switching the high-voltage, ultra-light-weight IGBTs (Insulated Gate Bipolar Transistors, IXEL40N400 by IXYS) are used. Eight IGBTs are used in total, two for charging the body actuators (right and left side), two for discharging them and another four for charging and discharging the tail fin actuators. The IGBT allow for a very dense assembly and 
therefore a small, light-weight HV switching unit, which is a necessity for using high-voltage in lighter-than-air technology. An IGBT Driver is needed to isolate the high-voltage ( $4000 \mathrm{~V}$ for driving the DE actuators) from the low-voltage (5 $\mathrm{V}$ for controlling the IGBTs). Additionally, different grounds are used for the low-voltage side and for the HV side. In case of an error both actuators are immediately discharged through the safety-relay.

For the high-voltage supply two HV modules (RA30-6 by Matsusada Precision Inc.) are used. For safety reasons the HV supply can be switched off immediately directly from the ground station or with an emergency switch integrated on the gondola. A summary of the electronic parts and their specifications can be found in Table 3.

Table 3: Technical specifications of the electronic parts in the airship gondola.

Technical specification gondola

$\begin{array}{ll}\text { Supply voltage } & 18-28 \mathrm{~V} \\ \text { Maximum input current } & 5 \mathrm{~A} \\ \text { Output voltage } & 0-4000 \mathrm{~V} \\ \text { Maximum output current } & 2 \times 5 \mathrm{~mA} \\ \text { Transmission frequency } & 2.4 \mathrm{GHz} \\ \text { Transmission range } & 300 \mathrm{~m} \text { line-of-sight, } 50 \mathrm{~m} \text { office setting }\end{array}$

\section{CONCLUSIONS AND DISCUSSION}

With the presented $8 \mathrm{~m}$ model airship the proof-of-concept has been done that the fish-like movement can be translated into air (Fig.10). Further, it was shown that we can use large-scale planar membrane DE actuators to act as artificial muscles on the airship and that they provide sufficient strain and force to induce the undulating fish-like movement that propels the airship.

Targeting this application we have studied the influence of size on the performance of the actuators. The experiments show that the large actuators behave expectedly and according to theory. In this context we have developed a novel setup for the testing of actuators in an agonist-antagonist configuration. Although we could show that the large-scale actuators behave similar to the small ones, much attention must be paid to details in manufacturing and design. Local defects and stress peaks may otherwise lead to problems concerning reliability and lifetime of the actuators. 


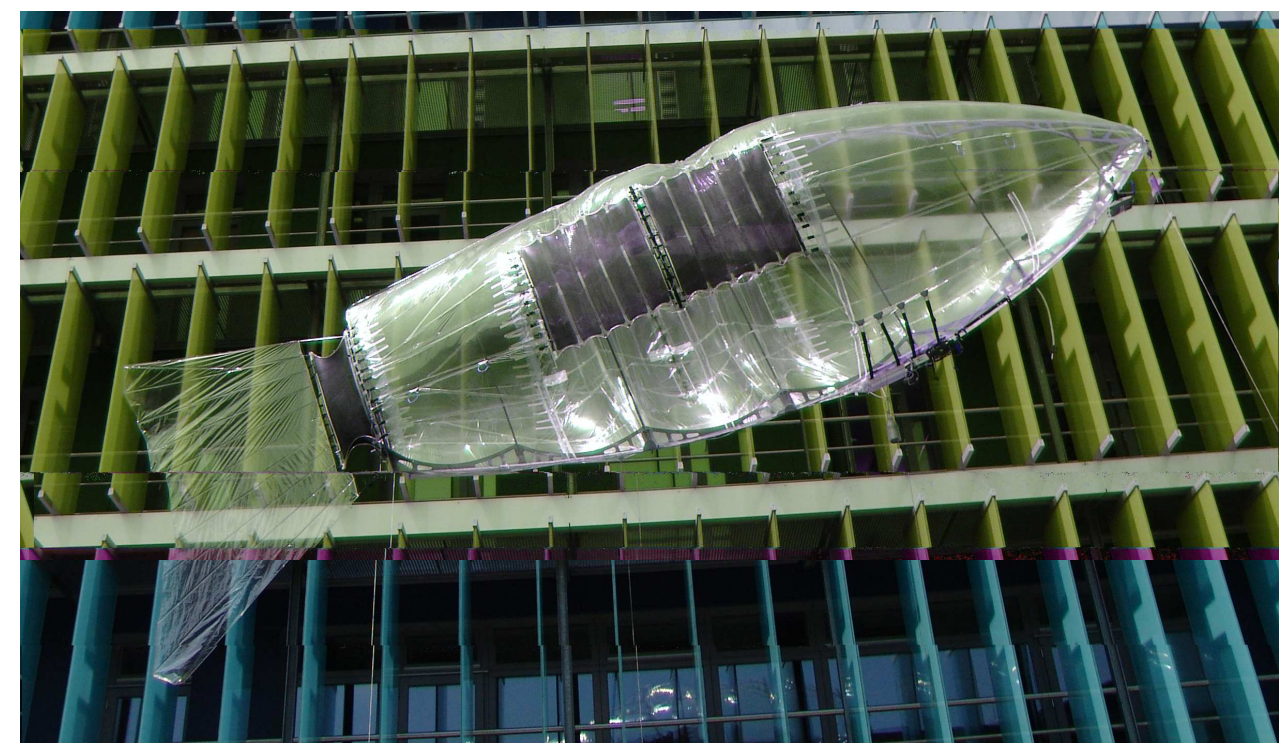

Fig. 10: Model airship of $8 \mathrm{~m}$ length with DE actuators (black) for fish-like propulsion.

The airship was activated with various combinations of frequency, amplitude and phase shift between body and tail fin movement (Table 4). A maximum velocity of $0.57 \mathrm{~m} / \mathrm{s}$ was reached. The differences of the resulting velocities are small though and we can not conclude on an optimal parameter combination. Runs with only the body or only the fin activated lead to the assumption that about half the thrust results from either of these movements. These tests are preliminary and incomplete though and an enhanced characterization of the fish-like movement will be done in the near future.

Table 4: Measured velocities from a testing series with variation in frequency, amplitude and phase shift.

\begin{tabular}{lllll}
\hline Frequency $[\mathrm{Hz}]$ & $\mathbf{V}_{\text {Fin }}[\mathbf{k V}]$ & $\mathbf{V}_{\text {Hull }}[\mathbf{k V}]$ & Phase shift $\left[{ }^{\circ}\right]$ & Velocity $[\mathbf{m} / \mathbf{s}]$ \\
\hline 0.1 & 2.5 & 2.5 & 72 & $\mathbf{0 . 2 3}$ \\
0.1 & 2.5 & 2.5 & 72 & $\mathbf{0 . 2 9}$ \\
0.15 & 3 & 2.5 & 45 & $\mathbf{0 . 4 3}$ \\
0.15 & 3 & 2.5 & 72 & $\mathbf{0 . 3 6}$ \\
0.2 & 2.5 & 2.5 & 72 & $\mathbf{0 . 5 7}$ \\
0.2 & 2.5 & 2.5 & 90 & $\mathbf{0 . 4 4}$ \\
0.2 & 3 & 2.5 & 0 & $\mathbf{0 . 4 3}$ \\
0.2 & 3 & 2.5 & 45 & $\mathbf{0 . 4 3}$ \\
0.25 & 3 & 2.5 & 72 & $\mathbf{0 . 4 5}$ \\
0.25 & 3 & 2.5 & 72 & $\mathbf{0 . 4 2}$ \\
0.2 & - & 2.5 & - & $\mathbf{0 . 2 4}$ \\
0.2 & 2.5 & - & - & $\mathbf{0 . 2 2}$ \\
\hline
\end{tabular}




\section{ACKNOWLEDGEMENT}

This work is funded by the board of directors of Empa. Many thanks go to Lars Paasche who did much of the practical work for the control system. The experimental work was supported by Marco Jakob, Emanuele Fazio, Milan Habovcik, Erich Fink and Martin Wähmer. The valuable discussions with Lukas Düring and Arne Schmidt are greatly acknowledged.

\section{REFERENCES}

[1] Sommer-Larsen, P., West, K., Kofod, G., Skaarup, S., Bay, L., Gravensen, P., Benslimane, M., "Electroactive Polymers as actuators - from gels to elastomers", Proc. Medical Plastics, Denmark (2001).

[2] Chiba, S., Waki, M., Kornbluh, R., Pelrine, R., "Innovative power generators for energy harvesting using electroactive polymer artificial muscles”, Proc. SPIE 6927, 92715-92715 (2008).

[3] Plante, J.S., "Dielectric Elastomer Actuators for Binary Robotics and Mechatronics", Diss. MIT Cambridge (2006).

[4] Michel, S., Bormann, A., Jordi, Ch., Fink, E., "Feasibility studies for a bionic propulsion system of a blimp based on Dielectric Elastomers“, Proc. SPIE 6927, S9270-S9270 (2008).

[5] Hertel, H., [Structure - form - movement], Reinhold Verlag, New York, (1966).

[6] Fish F.E., Lauder, G.V., "Passive and Active Flow Control by Swimming Fishes and Mammals", Annu. Rev. Fluid. Mech., 38, 193-224 (2006).

[7] Lochmatter, P., "Design and characterization of an active hinge segment based on soft dielectric EAPs," Sens. Actuators A: Phys., 141, 577-587 (2008).

[8] O’Brien, B., Calius, E., Xie, S., Anderson, I., “An experimentally validated model of a dielectric elastomer bending actuator”, Proc. SPIE 6927, T9270-T9270 (2008).

[9] Wissler, M., Mazza, E., "Electromechanical coupling in dielectric elastomer actuators", Sens. Actuators A: Phys., 138, 384-393 (2007). 